\title{
Metformin therapy in a hyperandrogenic anovulatory mutant murine model with polycystic ovarian syndrome characteristics improves oocyte maturity during superovulation
}

Mary E Sabatini, Lankai Guo, Maureen P Lynch, Joseph O Doyle, HoJoon Lee, Bo R Rueda and Aaron K Styer*

\begin{abstract}
Background: Metformin, an oral biguanide traditionally used for the treatment of type 2 diabetes, is widely used for the management of polycystic ovary syndrome (PCOS)-related anovulation. Because of the significant prevalence of insulin resistance and glucose intolerance in PCOS patients, and their putative role in ovulatory dysfunction, the use of metformin was touted as a means to improve ovulatory function and reproductive outcomes in PCOS patients. To date, there has been inconsistent evidence to demonstrate a favorable effect of metformin on oocyte quality and competence in women with PCOS. Given the heterogeneous nature of this disorder, we hypothesized that metformin may be beneficial in mice with aberrant metabolic characteristics similar to a significant number of PCOS patients. The aim of this study was to gain insight into the in vitro and in vivo effects of metformin on oocyte development and ovulatory function.

Methods: We utilized metformin treatment in the transgenic $o b / o b$ and $d b / d b$ mutant murine models which demonstrate metabolic and reproductive characteristics similar to women with PCOS. Results: Metformin did not improve in vitro oocyte maturation nor did it have an appreciable effect on in vitro granulosa cell luteinization (progesterone production) in any genotype studied. Although both mutant strains have evidence of hyperandrogenemia, anovulation, and hyperinsulinemia, only $d b / d b$ mice treated with metformin had a greater number of mature oocytes and total overall oocytes compared to control. There was no observed impact on body mass, or serum glucose and androgens in any genotype.

Conclusions: Our data provide evidence to suggest that metformin may optimize ovulatory performance in mice with a specific reproductive and metabolic phenotype shared by women with PCOS. The only obvious difference between the mutant murine models is that the $d b / d b$ mice have elevated leptin levels raising the questions of whether their response to metformin is related to elevated leptin levels and/or if a subset of PCOS women with hyperleptinemia may be responsive to metformin therapy. Further study is needed to better define a subset of women with PCOS that may be responsive to metformin.
\end{abstract}

Keywords: polycystic ovarian syndrome, metformin, hyperinsulinemia, oocyte, superovulation

\footnotetext{
* Correspondence: astyer@partners.org

Vincent Center for Reproductive Biology, Vincent Department of Obstetrics and Gynecology, Massachusetts General Hospital/Harvard Medical School, Boston, MA, USA
}

\section{$\int$ Biomed Central}

(C) 2011 Sabatini et al; licensee BioMed Central Ltd. This is an Open Access article distributed under the terms of the Creative Commons Attribution License (http://creativecommons.org/licenses/by/2.0), which permits unrestricted use, distribution, and reproduction in any medium, provided the original work is properly cited. 


\section{Background}

Polycystic ovarian syndrome (PCOS) is a complex, multifactorial endocrinopathy which affects approximately 4 to $10 \%$ of reproductive-aged women. Because it is a highly heterogeneous syndrome with a variable clinical presentation, criteria for diagnosis have been debated. Many authorities utilize the guidelines of Rotterdam/ASRM-sponsored PCOS Consensus Workshop Group [1] and require the presence of at least two of the following: oligoovulation and/or anovulation, evidence of clinical or biochemical hyperandrogenism, and the presence of polycystic ovarian morphology during ultrasound examination.

PCOS is associated with several significant morbidities including infertility, obesity, insulin resistance, type 2 diabetes, dyslipidemia, and endometrial hyperplasia [2-6]. Proposed etiologies for PCOS include hypothalamic-pituitary dysynchrony, aberrant gonadotropin pulsatile secretion, granulosa/theca cell dysfunction, and various metabolic derangements including exaggerated ovarian androgen production, hyperinsulinemia, and insulin resistance [7-12]. Still, it is unclear whether the primary source of metabolic derangement is ovarian, hypothalamic/pituitary, or a combination of several systemic factors.

Several therapeutic options have been utilized to treat PCOS associated ovulatory dysfunction and infertility. These include weight loss, clomiphene citrate, exogenous gonadotropins, insulin sensitizers, and ovarian diathermy. Since its introduction as a treatment for type 2 diabetes in the United States in 1996, metformin also emerged as a common treatment for infertile women with PCOS [13-15]. Despite widespread and continued use, the efficacy of metformin as a treatment for PCOS remains unproven and controversial. Metformin has been shown by some investigators to result in weight loss, normalization of menstrual cycles, and an improvement of conception rates following therapies such as ovulation induction and controlled ovarian hyperstimulation prior to in vitro fertilization (IVF) [16-19]. In contrast, other studies have demonstrated that metformin does not offer any clinical benefit [20-22].

Metformin has been primarily characterized as an activator of AMP activated kinase (AMPK) [23]. AMPK serves as a sensor of energy status at the cellular level and is activated by an elevated AMP/ATP ratio. Activation of AMPK may induce catabolic processes which generate ATP and reduce anabolic processes which consume ATP. It can also serve as an energy sensor in several organs. For example, small decreases in glucose result in AMPK activation and decreased pancreatic insulin production with increase hypothalamic-driven feeding behavior [12,24-27]. Moreover, AMPK has evolved in higher organisms to be a highly complex regulator of cytokine function where leptin and adiponectin activate AMPK in muscle to increase glucose uptake and fatty acid oxidation $[28,29]$. The significance of metformin's role as an AMPK modulator is uncertain in reproductive processes such as oocyte maturation, ovulation, and luteinization.

To date, there is limited evidence demonstrating a consistent physiologic effect of metformin on oocyte development, ovulatory function, and fecundity in animal models. Previous data in the bovine model have demonstrated that metformin results in inhibition of maturation of denuded (DO) and non denuded oocytes. A similar effect was seen with a specific AMPK activator (AICAR), implying that metformin's inhibitory action may be mediated in part by AMPK activation in the oocyte [30]. Similarly, in vitro studies using porcine oocytes have shown that metformin prevents the maturation of the oocyte when it is part of the cumulus oophorus complex $(\mathrm{COC})$. However, it did not prevent maturation of the porcine DO [31]. The AMPK activator, AICAR, has been shown to induce meiotic resumption in both mouse DO and COC in vitro, whereas this effect is blocked by Compound $\mathrm{C}$, a specific AMPK inhibitor [32]. Metformin has also been shown to inhibit progesterone production in vitro through an AMPK mediated pathway in a number of cell types derived from several different species [33-35]. Notably, in vitro metformin concentrations of all aforementioned studies were supraphysiologic $(0.1-2$ $\mathrm{mM})$. According to Lee and Kwon [36], serum concentrations in physiologic doses in humans are much lower, at approximately $8-10 \mu \mathrm{M}$.

Given the inconsistent results of published bovine and murine studies, and the controversy surrounding metformin's efficacy in PCOS-related ovulatory dysfunction and infertility, the goal of this study was to gain better insight into the effects of metformin on oocyte development and ovulation in mouse models which demonstrate metabolic and reproductive characteristics of women with PCOS. We utilized two different leptin mutant mouse strains. Both models, B6.Cg-m+/+Lep $/ \mathrm{J}$ or $o b / o b$ and the B6.V$L e p^{d b} / \mathrm{J}$ or $\left.d b / d b\right)$, exhibit obesity, hyperphagia, a diabeteslike syndrome of hyperglycemia, glucose intolerance, elevated plasma insulin, and subfertility $[37,38]$. The $o b / o b$ strain does not produce endogenous leptin while the other strain, $d b / d b$, possess a nonfunctional leptin receptor and has elevated systemic leptin levels. We hypothesized that metformin therapy will have an effect on oocyte maturation and/or ovulatory function in $o b / o b$ and $d b / d b$ animals compared to wild type (WT) mouse strains.

\section{Methods \\ Animal studies \\ Animals}

Eight week-old female C57BL6 wild-type (WT), leptin deficient (B6.Cg-m+/+Lep $\left.p^{o b} / \mathrm{J}, o b / o b\right)$ and leptin 
receptor mutant (B6.V-Lep $d b / \mathrm{J}, d b / d b)$ mice (Jackson Laboratory, Bar Harbor, ME) were housed in the animal facility at the Massachusetts General Hospital in accordance with the National Institutes of Health standards for the care and use of experimental animals. Rooms provided a controlled temperature range of $\left(22-24^{\circ} \mathrm{C}\right)$ on a 14-hour light, 10-hour dark cycle. Mice were given food and water ad libitum. All animal procedures described were approved by the Subcommittee on Research Animal Care at Massachusetts General Hospital.

\section{In vitro cultures}

Thirty six to forty hours following injection of $10 \mathrm{IU}$ pregnant mare serum gonadotropin (PMSG) (Sigma Aldrich, ST. Louis, MO, \# G4877), animals were euthanized with intraperitoneal injection of Avertin $0.5 \mathrm{mg} / \mathrm{ml}$ followed by cervical dislocation, and the ovaries of each respective genotype were placed in DMEM supplemented with $10 \%$ fetal bovine serum (FBS). Follicles were punctured using a 28 gauge needle. For oocyte experiments, germinal vesicle (GV) oocytes were manually denuded with a glass pipette, pooled, and divided into DMEM with $10 \% \mathrm{FBS}$ with or without insulin and/or varying concentrations of metformin. Metformin (Sigma Aldrich, St. Louis, MO, \#D150959) for in vitro cultures was dissolved in Dulbecco's Modified Eagle's Medium (DMEM, Invitrogen 21063029, Carlsbad, CA) to $0.5 \mathrm{M}$, filter sterilized and diluted immediately into culture. Oocytes were incubated at $37^{\circ} \mathrm{C}$ with $5 \% \mathrm{O}_{2}$. Maturity was assessed by light microscopy after 40 hours in culture. Oocytes were classified into the following groups: germinal vesicle oocytes (GV), germinal vesicle breakdown oocytes (GVBD), oocytes that have completed meiosis I (M1) (presence of first polar body) and fragmented (atretic) oocytes. Each experiment utilized 5 mice of each genotype (WT, ob/ob, $d b / d b$ ) with 15 oocytes in each in vitro metformin concentration group per replicate. Each experiment was performed in quadruplicate.

For granulosa cell experiments, ovaries were placed in phosphate buffered saline (PBS), and follicles were punctured as above. After manually removing residual ovarian tissue, the follicular contents were spun at $200 \times \mathrm{g}$ for 5 minutes at $4^{\circ} \mathrm{C}$. The supernatant was removed and the pellets were resuspended in $1 \mathrm{~mL}$ of Weymouth's Solution (Invitrogen, Carslbad, CA, \#11220035) supplemented with $10 \%$ FBS, Insulin-Transferrin-Selenium-A Supplement (Invitrogen, Carslbad, CA \#51300-044, diluted 1:100), Penicillin-Streptomycin-Glutamine (Invitrogen, Carslbad, CA \#10378, diluted 1:100) and sodium pyruvate (Invitrogen, Carslbad, CA \#11360-070 diluted 1:100). Ten microliters was mixed with $10 \mu \mathrm{L}$ of trypan blue and viable granulosa cells were counted with a hemocytometer. Cells were then diluted to a concentration of $5 \times 10^{4} / \mathrm{mL}$, and $1 \mathrm{~mL}$ was placed in a well of a
12 well plate. Culture medium was changed the following day (day 1 in culture) with the same medium except containing 1\% FBS. Medium was changed every other day thereafter and frozen and stored as below.

\section{Progesterone assays}

Medium was removed from granulosa cell cultures on the day indicated and frozen at $-20^{\circ} \mathrm{C}$. Medium was then thawed and prepared per manufacturer's protocol (DRG EIA 1561, DRG International, Mountainside, NJ). Samples that contained greater than $40 \mathrm{ng} / \mathrm{mL}$ of progesterone underwent serial dilution so that readings fell within the standard curve of the assay $(0.3-40 \mathrm{ng} / \mathrm{mL})$ using a calibrated reader at $450 \mathrm{~nm}$. Granulosa cells were pooled and subjected to treatments. Within each experiment, each sample was run in duplicate per manufacturer's recommendation. Each experiment was performed in triplicate.

\section{Ovulation induction experiments}

Six week old female mice were provided water alone or water which contained metformin at a concentration of $0.1 \mathrm{mg} / \mathrm{ml}$ for 7 weeks (treatment group). Because the murine estrous cycle is approximately 4.5 days, seven weeks is equivalent to approximately 12 estrous cycles. Metformin was added to daily water supply at a concentration of $0.1 \mathrm{mg} / \mathrm{mL}$. Based upon the average water consumption of $6 \mathrm{~mL}$ of water per day of the C57BL6 mouse [39], this would amount to each mouse in the treatment group receiving a dose of metformin which approximates a standard adult human dose of 2,000 mg per day $(28 \mathrm{mg} /$ $\mathrm{kg} /$ day). Animals, which underwent superovulation, were injected with PMSG 10 IU IP followed 48 hours later by human chorionic gonadotropin (hCG) (Sigma Aldrich, St. Louis, MO, \#CG10) 10 IU IP. Sixteen to eighteen hours after hCG treatment, serum glucose concentration was analyzed using a One Touch Ultra glucometer (LifeScan, Johnson and Johnson Subsidiary, 1000 Gibraltar Drive, Milpitas, CA). Subsequently, animals were weighed and euthanized with intraperitoneal injection of Avertin 0.5 $\mathrm{mg} / \mathrm{ml}$ followed by cervical dislocation. Blood and oviducts were collected. Oocytes were removed from oviducts, counted and assessed for maturity and classified into the previously mentioned groups. Serum total testosterone was tested by radioimmunoassay (RIA) using the DPC Coat-A-Count RIA kit (Diagnostics Products Corporation, Los Angeles, CA). Experiments were performed in triplicate.

\section{Ovarian follicular counts}

Six-week old female mice were given metformin orally as above. At the end of the seven week period, animals were euthanized. Ovaries were dissected and were immediately fixed overnight in Deitricks fixative $(0.34 \mathrm{~N}$ glacial acetic acid, $10 \%$ formalin, $28 \%$ ethanol) for histological assessment and processed for paraffin embedding. Serial sections ( 5 micrometers) were cut and dried for 24 hours. 
Sections were deparaffinized, rehydrated, and stained with hematoxylin for 10 minutes. Slides were counterstained with picric acid methyl blue for six minutes, dehydrated, coverslipped, and allowed to dry for 24 hours. Counts of primordial (single layer of flattened granulosa cells, preantral (single layer cuboidal granulosa cells), preantral (2-4 granulosa cell layers) and antral (> 4 granulosa cell layers with distinct antrum visible) follicles with visible nucleoli were performed on every fifth section in a blinded fashion according to previously described histomorphometric techniques $[40,41]$. Follicles were counted in 3 independent mice per genotype.

\section{Statistical analysis}

Data were expressed as mean \pm SEM of respective groups (experiments performed in triplicate or more as indicated). Data were analyzed using $t$ test or two-way ANOVA with post hoc Tukey test. $P<0.01$ designated as a statistically significant difference for ANOVA and $P<0.05$ for comparison not using ANOVA.

\section{Results}

In vitro metformin treatment of mouse oocytes

There was a significant difference in the percent of oocytes completing meiosis 1 (M1) in the $1000 \mu \mathrm{M}$ treatment group relative to the control group $(0 \mu \mathrm{M})$ in WT ( $\mathrm{p}=$ $0.01)$, and $o b / o b(\mathrm{p}=0.01)$ mice (Figure 1$)$. The percent oocytes which completed M1 was 0.58 fold fewer in WT and 0.50 fold fewer in $o b / o b$. There was no difference in percent oocytes completing M1 in vitro in the $d b / d b$ group.

\section{In vitro metformin exposure of mouse granulosa cell} cultures

There was no significant difference in progesterone levels in the media of cultured granulosa cells treated with any concentration of metfomin at any time point assessed in any genotype relative to control (Figure 2).

\section{In vivo metformin treatment in $\mathrm{WT}$, ob/ob, and $\mathrm{db} / \mathrm{db}$} mice

Following exposure with oral metformin for seven weeks (12 estrous cycles) and superovulation, significantly more mature oocytes and a greater total overall quantity of oocytes were recovered from $d b / d b$ mice. Specifically, 1.77 fold more mature oocytes $(\mathrm{p}=0.018)$ and 1.51 fold more total oocytes overall $(\mathrm{p}=0.04)$ were obtained following superovulation of metformin exposed $d b / d b$ mice relative to controls (no treatment) (Figure $3 \mathrm{C}$ ). There was no difference in the quantity and proportion of mature oocytes obtained after superovulation of metformin exposed WT and $o b / o b$ mice (Figure 3A, 3B). Animal weight (Figure 3D) and serum testosterone levels (Figure $3 \mathrm{~F}$ ) were unchanged during the metformin treatment course for any genotype. Blood glucose levels did not differ in response to metformin treatment in any genotype (Figure $3 \mathrm{E}$ ). Both $o b / o b$ and $d b / d b$ mice demonstrated significantly greater baseline testosterone levels, serum glucose levels, and body mass (weight) than WT animals ( $\mathrm{p}<$ $0.01)$.

\section{Gross ovarian anatomy}

This analysis revealed that the control $d b / d b$ mice demonstrated a two fold greater total non atretic follicular count relative to control WT animals $(\mathrm{p}=0.01)$ (Figure 4D). Overall, animals treated with metformin did not demonstrate any change in the total follicle numbers or number in any specific follicular stage in any genotype studied compared to their respective controls.
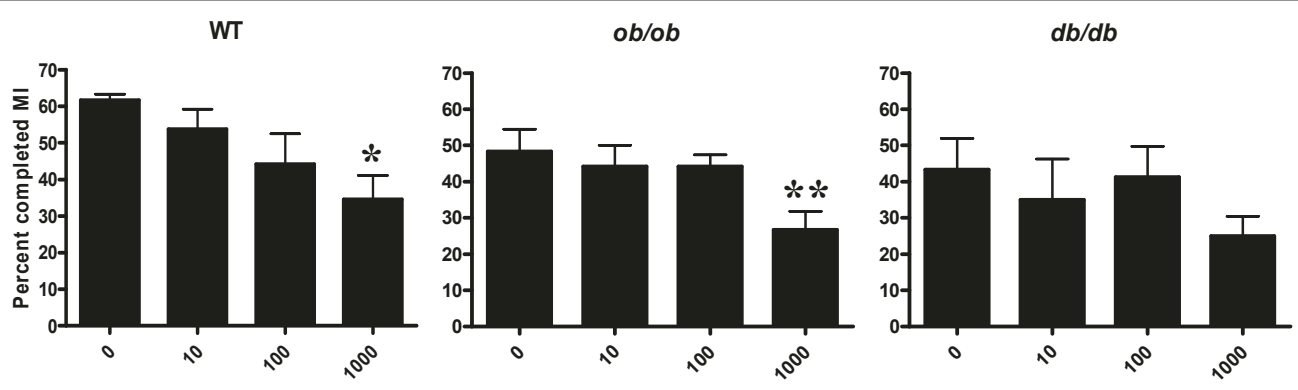

\section{Metformin concentration, micromolar}

Figure 1 Effect of metformin on in vitro oocyte maturation. The vertical axis represents the percent of oocytes which completed meiosis I $(\mathrm{MI})$ in culture. The horizontal axis shows in vitro metformin concentration (micromolar [ $\mu \mathrm{M}]$ ). Each experiment utilized 5 mice for each genotype $(W T, o b / o b, d b / d b)$ with 15 oocytes in each in vitro metformin concentration group per replicate. Each experiment was performed in quadruplicate. Error bars are SEM. Oocytes treated with metformin concentration of $1000 \mu \mathrm{M}$ demonstrated a reduction in percent oocytes which completed $\mathrm{Ml}$ compared to control $(0 \mu \mathrm{M})$ in $\mathrm{WT}$ and ob/ob. Asterisks indicate statistical significance of $p<0.05$ for WT and ob/ob genotypes following comparison ( ${ }^{*}$ and ${ }^{* *} p=0.01$, t test). 


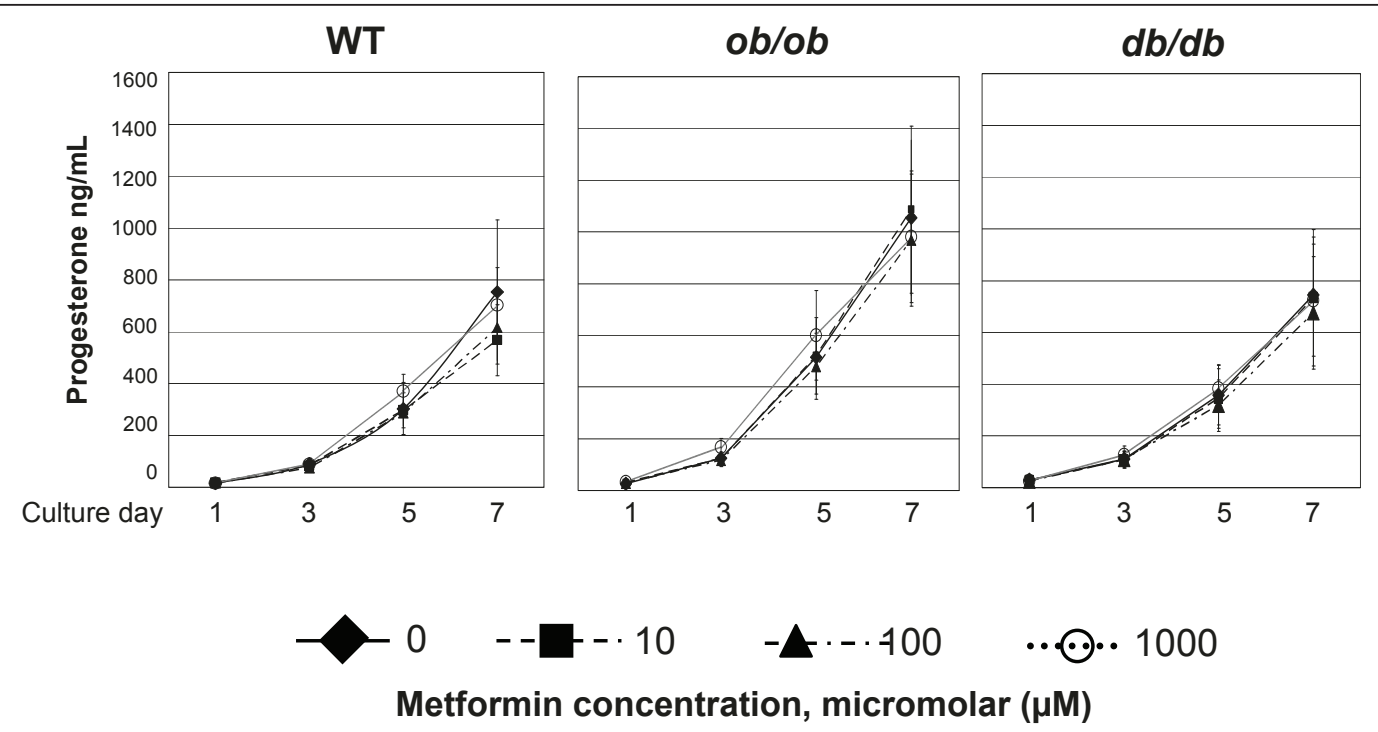

Figure 2 In vitro granulosa cell culture progesterone levels following exposure to metformin during seven days of metformin treatment. Experiments were performed with 5 mice per genotype. Granulosa cells were pooled, divided into groups by metformin concentration and duration of culture, and media was collected for analysis. Experiments were performed in triplicate. Error bars are SEM. Compared to respective controls, no difference $(P>0.05, t$ test) was observed in progesterone levels of media in any metformin concentration during any time point in any genotype.
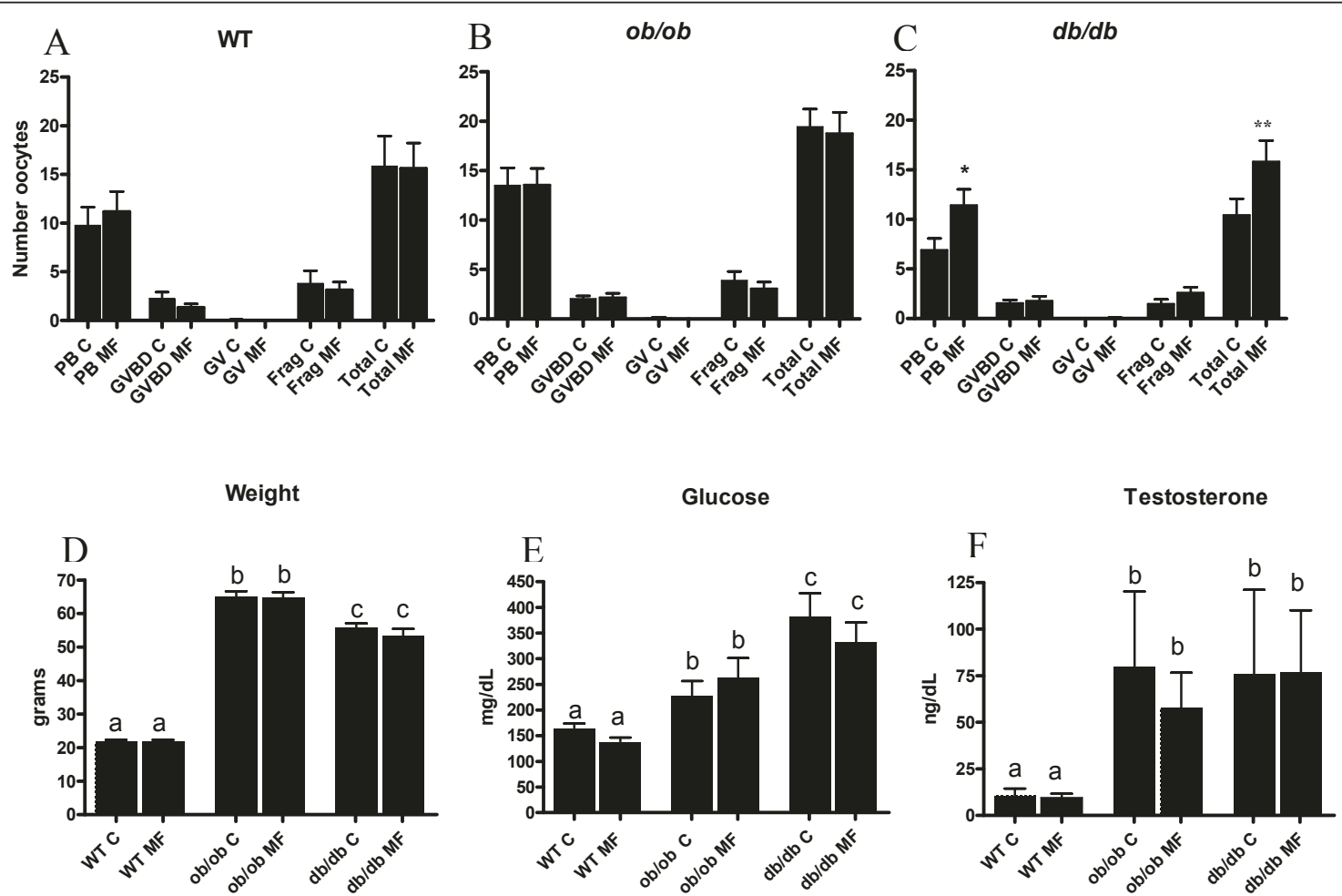

Figure 3 Reproductive and metabolic effects of oral metformin pretreatment during superovulation. For $A-C, C=c o n t r o l, M F=$ metformin, $\mathrm{PB}=$ mature oocyte with polar body, GVBD = germinal vesicle break down oocyte, $\mathrm{GV}=$ immature germinal vesicle oocyte, frag = fragmented oocyte. Experiments were performed in triplicate. Error bars are SEM. A statistically significant increase in the quantity of ovulated mature oocytes (PB MF) and total number of oocytes ovulated (Total MF) was observed during superovulation in $d b / d b$ mice compared to control (* denotes $p=0.018$ and ** denotes $p=0.04$, t test) (C). ob/ob and $d b / d b$ mice demonstrated greater respective body mass (D) and testosterone levels (F) compared to WT mice. Metformin did not have an appreciable effect on any metabolic measure in any genotype relative to control $(D, E, F)$. Different designated letters among genotypes in $D, E$, and $F$ indicate statistical difference with $p<0.01$ (ANOVA). 

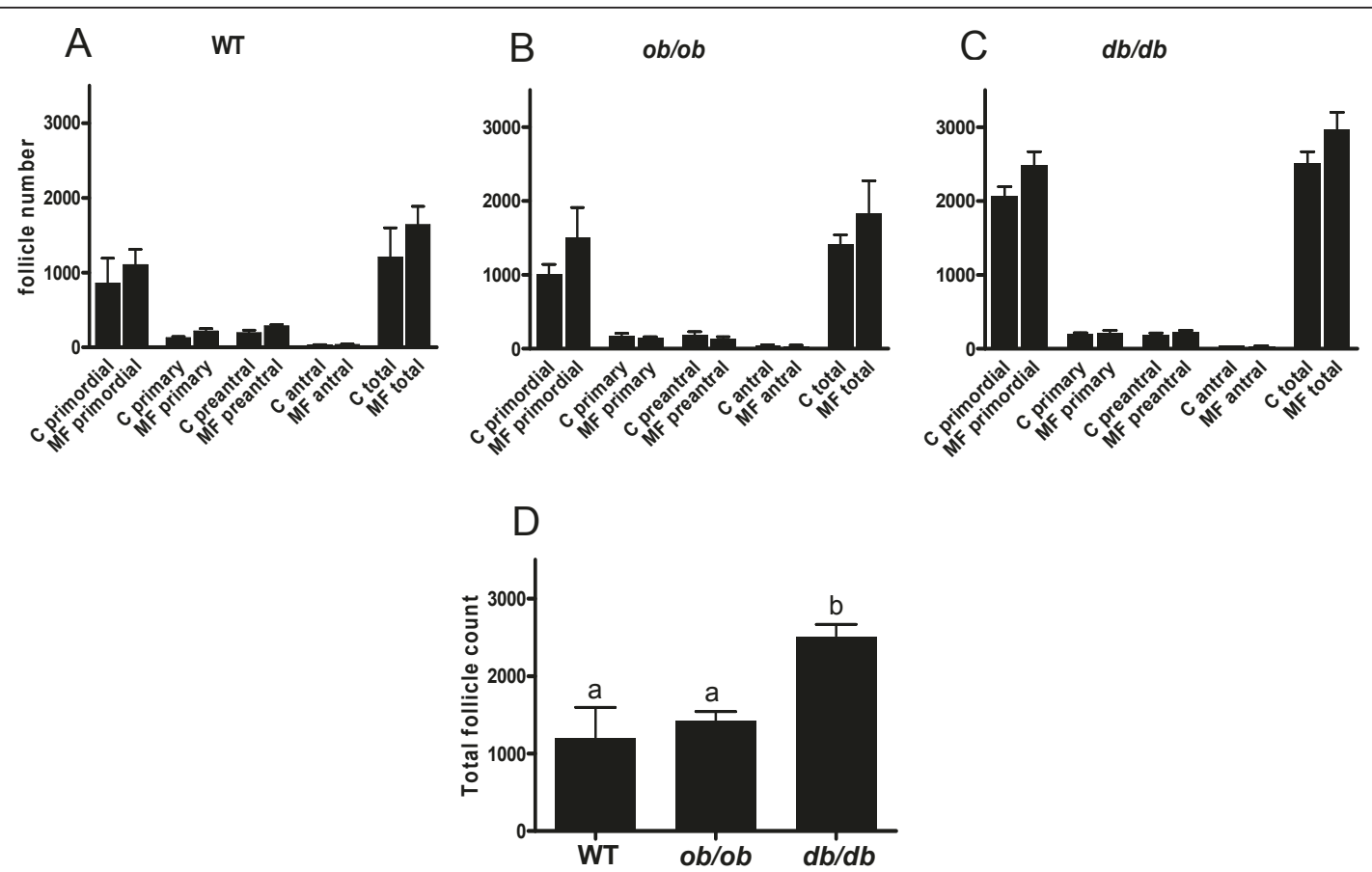

Figure 4 Ovarian follicular counts (non atretic) following in vivo metformin exposure. Horizontal axis indicates follicle stage. Follicle counts were performed in mice $(N=3)$ who underwent 7 weeks of oral metformin treatment or no treatment (control) $(A, B, C)$. C = control, MF = metformin. All counts of this figure included 3 replicates with $N=1$ mouse. Error bars represent SEM. Follicular counts (of any stage) did not change (relative to control group) following metformin treatment. Overall, $d b / d b$ mice demonstrated a significantly greater total follicular endowment (sum of all non atretic follicle stages) than WT and ob/ob mice (D). Different designated letters among genotypes in D indicates statistical difference with $p=0.01$ (ANOVA).

\section{Discussion}

Distinct features in women with PCOS, insulin resistance and compensatory hyperinsulinemia, lead to hyperandrogenemia due to increased ovarian androgen production and decreased production of sex hormone binding globulin $[42,43]$. Since hyperinsulinemia has been implicated as a significant cause of anovulation, many investigators hypothesized that a reduction of systemic insulin serum levels would result in an improvement of ovulatory function and overall fecundity in PCOS women. Initial studies investigating the use of metformin in PCOS demonstrated a beneficial role of metformin as an ovulation induction agent compared to placebo, clompihene citrate (CC), and $\mathrm{CC}$ and metformin combined [16]. However, two subsequent large, prospective, double blind studies did not demonstrate any benefit for metformin treatment in women with PCOS in terms of ovulation rate and pregnancy outcome $[44,45]$. Despite a long track record of metformin use in type 2 diabetes, it still remains unclear whether it provides a beneficial reproductive effect as an adjuvant therapy in women with PCOS. Furthermore, if there is a beneficial reproductive effect of metformin, it is unclear whether it acts locally at the level of the ovary, pituitary, hypothalamus, or on a more systemic level. In this study, we have demonstrated for the first time, that metformin confers significant in vitro and in vivo effects on oocyte maturation in mouse strains with metabolic and reproductive characteristics of PCOS. Specifically, we demonstrate a reduction in the completion of meiosis 1 by oocytes in vitro following metformin exposure in WT and $o b / o b$ mice, and an increase in the yield of mature oocytes and total overall oocytes following continuous dietary metformin for 7 weeks prior to superovulation in a $d b / d b$ in vivo model.

We hypothesized that treatment with the insulin sensitizer, metformin, would have an impact on oocyte maturation and/or ovulation in a PCOS-like mouse strain with a hyperinsulinemic and anovulatory phenotype. Previous studies examining the effects of metformin, have focused on specific compartments of the ovary, namely the oocyte and granulosa cells in WT animals (congenic mice and outbred strains of cows and pigs), with normal ovulatory function [30-32]. In vitro studies have demonstrated direct effects of metformin on the ovary, which involve inhibition of basal and insulin stimulated granulosa cell P450 aromatase via MEK/ ERK (MAPK kinase) activation [46]. Similar to previously published studies detailing an inhibitory effect of metformin on in vitro oocyte maturation [30,31], the 
results of this study demonstrated that metformin reduced in vitro maturation of the mouse oocyte. Specifically, meformin exerted a significant reduction of maturation of oocytes derived from WT and $o b / o b$ mice, but not in $d b / d b$ mice. Notably, the in vitro concentration of metformin which demonstrated this finding was at the highest concentration, and may represent an extremely elevated in vivo serum level which surpasses the typical human metformin dose of $2000 \mathrm{mg}$ daily dose (approximately $10 \mu \mathrm{M}$ ). These collective findings raise the possibility that this effect may be an artifact of toxicity of the high levels of metformin. Alternatively, these findings may be the result of in vitro conditions, which may not be directly applicable to in vivo conditions.

Based upon previous data [47] which demonstrated an antiapoptotic effect of metformin on luteinized granulosa cells in PCOS patients undergoing IVF, it may be expected that metformin treatment would result in elevated progesterone levels in conditioned media from cultured granulosa cells derived from both transgenic mouse models which share PCOS characteristics. However, there was no obvious effect of increasing doses of metformin on progesterone levels in conditioned media derived from granulosa cells in any genotype. Therefore, it can be inferred that there was no significant change in cell number. The differences in our results may be attributed to species to species variability in response to metformin or may reflect the complexity of steroidogenesis, which likely involves multiple pathways independent of those regulated by metformin.

In vivo studies examined the chronic effects of metformin pretreatment on oocyte development and ovulatory performance in WT, $o b / o b$ and $d b / d b$ mouse strains during superovulation. With the use of $0.1 \mathrm{mg} / \mathrm{ml}$ metformin in drinking water (approximate to human dose of $2000 \mathrm{mg}$ per day), these experiments demonstrated that metformin significantly increased the number of mature oocytes ovulated by 1.77 fold $(p=0.018)$ and the total overall number of oocytes released by 1.51 fold ( $\mathrm{p}=0.04)$ in $d b / d b$ mice during superovulation. Interestingly, this same result was not observed in the $o b / o b$ mouse strain, which shares many phenotypic similarities (obesity, hyperglycemia, hyperinsulinemia, and infertility with anovulation). In contrast to the $o b / o b$ mouse, which lack endogenous leptin production, the $d b / d b$ mouse has elevated systemic leptin levels. An explanation of the results seen only in the $d b / d b$ strain may be due to a possible effect of metformin on this animal's endogenously elevated leptin levels. Notably, there are preliminary data describing the reduction of leptin by metformin in women with PCOS [48]. However, the fact that the $d b / d b$ mice lack a functional cognate receptor leptin receptor (long isoform) would imply that any change incurred by a decrease in leptin may be indicative of leptin eliciting a response through the less characterized short form of the OB receptor or via an unrecognized alternative receptor.

Given the known role of hyperinsulinemia and hyperandrogenemia in PCOS anovulation, it may also be initially inferred that the metformin treated $d b / d b$ genotype displayed improved glucose control and weight loss compared to other mouse strains. However, there were no significant differences in weight, glucose, or testosterone levels in any metformin treated mouse strain compared to controls. This observation in the $d b / d b$ mouse may signify a more pronounced, yet less detectable intrafollicular effect of hyperinsulinemia in this transgenic genotype. In line with prior observations of dysfunctional steroidogenesis and folliculogenesis in PCOS [49], correction of this metabolic derangement with the insulin sensitizer, metformin, may have established a more favorable intrafollicular insulin environment and may have optimized ovulatory performance, resulting in an improvement in the production of mature oocytes during superovulation in the $d b / d b$ strain. Several authors have recently published findings which support a possible direct impact of metformin on the ovary. Stimulation of lactate production and activation of AMPK in granulosa cells by this compound has been proposed as a mechanism of improving follicular and oocyte development [50]. Additionally, the findings of Palomba et al. demonstrate a significant effect of metformin on intrafollicular insulin growth factor 2, several insulin growth factor binding proteins, estradiol, and androgen levels in women with PCOS [51].

Although there is not a single ideal animal model for PCOS, several reproductive and metabolic features commonly observed in PCOS are present in the animal models utilized in the present study. As highlighted previously, there are other additional mouse and rat models which have been utilized to study PCOS [52]. Unfortunately, some primarily possess metabolic traits, others demonstrate only reproductive characteristics, while others possess some combination of both $[37,38,52,53]$. As is true with other models, the mouse strains used in this study do not perfectly simulate human PCOS. To this end, one model will not be completely representative of all human PCOS phenotypes. Investigation in many different models will be likely required to gain a more comprehensive understanding of the metabolic and reproductive aspects of this syndrome. Since the $o b /$ $o b$ and $d b / d b$ mice share both reproductive and metabolic characteristics of women with PCOS, it was most appropriate to utilize these strains to investigate the potential reproductive effects of metformin in a hyperinsulienmic and anovulatory in vivo model. Although the exact mechanism of metformin has not been elucidated, 
it has been shown to be an activator of AMPK. The inhibitory effects of metformin at the level of the oocyte have been inferred from various mammalian studies using the AMPK activator (AICAR) and AMPK inhibitor Compound C [30-32]. Unfortunately, it is difficult to directly assess the discreet physiologic role of metformin AMPK activation in reproduction in this model. In future studies, it may be possible to assess the role of the metformin AMPK pathway in another model since a group of investigators have demonstrated that the kinase LKB1 mediates glucose homeostasis in liver and the therapeutic effects of metformin [54]. In order to definitively characterize the function of metformin via the AMPK pathway, the use of the LKB1 deficient mouse may provide additional insight into AMPK mediated local and systemic effects of metformin from a metabolic and reproductive standpoint.

Due to the wide variation of metabolic and reproductive characteristics in women with the polycystic ovarian syndrome, it has become a difficult task to identify if any PCOS phenotype may benefit from metformin. The unpredictable extent to which a specific end organ is affected by insulin resistance or hyperinsulemia (e.g. ovary of a woman with PCOS) is likely contributory to the inconsistent results of previous studies examining metformin use in PCOS [54]. Given the continued uncertainty regarding the clinical reproductive benefit of metformin use for PCOS associated infertility, a study such as this, can assist the field in determining whether this adjuvant therapy is of tangible benefit in clinical practice. In the hyperinsulinemic and hyperandrogenic anovulatory leptin $o b / o b$ and $d b / d b$ mutant mouse strains, no significant effect of metformin was observed at physiologic levels in vitro at the level of oocyte or granulosa cells to increase oocyte maturity or progesterone production respectively. As hypothesized, a beneficial in vivo effect was demonstrated in the $d b / d b$ strain as seen by an improvement of the yield of mature oocytes during superovulation. When considering our findings, it may be reasonable to speculate that metformin may act to optimize oocyte development and production by the local and/or systemic reduction of hyperinsulinemia, androgen and leptin production, as well as by the reduction of inappropriately high intrafollicular estradiol levels (seen in PCOS patients) by attenuation of aromatase activity as highlighted previously [46,49]. In light of recent findings which suggest that metformin may act via an insulin dependent mechanism in the human ovary, this treatment may confer a significant effect on oocyte development and ovulatory performance in the $d b d b$ mouse and a subset of similarly hyperleptinemic and hyperinsulinemic women with PCOS [55], Additionally, the larger follicular endowment of $d b / d b$ mice, compared to other genotypes, may also contribute an unknown influence on oocyte maturation and development during superovulation.

\section{Conclusions}

In summary, by using transgenic mouse models with characteristics of PCOS, we have demonstrated a significant in vivo reproductive effect of metformin use in a specific mouse strain. These findings may imply that a specific subset of women with the PCOS reproductive phenotype may potentially benefit from metformin, while the majority with this syndrome will not. Additionally, the observed in vivo effects of metformin in the hyperleptinemic $d b / d b$ strain may infer that a subset with the PCOS reproductive phenotype characterized by hyperinsulinemia, anovulation, and hyperleptinemia may be more responsive to metformin than those without elevated leptin levels. With the use of a transgenic mouse strain such as $d b / d b$, our findings demonstrate a possible role of metformin to optimize ovulatory performance during superovulation in mice with a specific reproductive and metabolic phenotype. To this end, future studies utilizing the $d b / d b$ mouse strain and other PCOS-like murine models will provide the foundation for future investigation to clearly determine the utility of metformin treatment in the human model of PCOS.

The authors declare that they have no competing interests.

\section{Acknowledgements}

We would like to express our gratitude to Kelle H. Moley MD (Washington University School of Medicine, St. Louis, MO) for her assistance in the design of this study.

Mary E. Sabatini MD PhD was a recipient of National Institutes of Health Loan Repayment Program Award (2006-2008)

\section{Authors' contributions}

MES cared for all animals used in the study, performed a majority of all in vitro and in vivo experiments, and participated in manuscript preparation. All statistical analysis was performed by MES and reviewed by AKS and BRR. LG conducted in vitro progesterone assays and ovarian follicular counting experiments. MPL contributed to the conception and formulation of the study design and and to critical analysis of results. JOD assisted with animal care and progesterone assays. HJL served as an additional participant during the assessment of ovarian maturity in the in vitro studies, oocyte counts, and assessments during the superovulation studies. BRR participated in the conception and design of the study, critical analysis of data, and manuscript preparation. AKS is responsible for the original conception of the study, coordination and supervision of experiments, critical analysis of data, and preparation of the manuscript. All authors read and approved the final manuscript.

Received: 25 March 2011 Accepted: 23 May 2011 Published: 23 May 2011

\section{References}

1. Revised 2003 consensus on diagnostic criteria and long-term health risks related to polycystic ovary syndrome (PCOS), Hum Reprod. 19, 41-47 (2004)

2. MO Goodarzi, R Azziz, Diagnosis, epidemiology, and genetics of the polycystic ovary syndrome. Best Pract Res Clin Endocrinol Metab. 20, 193-205 (2006). doi:10.1016/j.beem.2006.02.005 
3. KH Park, JY Kim, CW Ahn, YD Song, SK Lim, HC Lee, Polycystic ovarian syndrome (PCOS) and insulin resistance. Int J Gynaecol Obstet. 74, 261-267 (2001). doi:10.1016/50020-7292(01)00442-8

4. T Apridonidze, PA Essah, MJ luorno, JE Nestler, Prevalence and characteristics of the metabolic syndrome in women with polycystic ovary syndrome. J Clin Endocrinol Metab. 90, 1929-1935 (2005). doi:10.1210/ jc.2004-1045

5. EO Talbott, JV Zborowski, JR Rager, MY Boudreaux, DA Edmundowicz, DS Guzick, Evidence for an association between metabolic cardiovascular syndrome and coronary and aortic calcification among women with polycystic ovary syndrome. J Clin Endocrinol Metab. 89, 5454-5461 (2004). doi:10.1210/jc.2003-032237

6. OC Pillay, LF Te Fong, JC Crow, E Benjamin, T Mould, W Atiomo, PA Menon, AJ Leonard, P Hardiman, The association between polycystic ovaries and endometrial cancer. Hum Reprod. 21, 924-929 (2006)

7. R Voutilainen, S Franks, HD Mason, H Martikainen, Expression of insulin-like growth factor (IGF), IGF-binding protein, and IGF receptor messenger ribonucleic acids in normal and polycystic ovaries. J Clin Endocrinol Metab. 81, 1003-1008 (1996). doi:10.1210/jc.81.3.1003

8. CW Burger, T Korsen, H van Kessel, PA van Dop, FJ Caron, J Schoemaker, Pulsatile luteinizing hormone patterns in the follicular phase of the menstrual cycle, polycystic ovarian disease (PCOD) and non-PCOD secondary amenorrhea. J Clin Endocrinol Metab. 61, 1126-1132 (1985). doi:10.1210/jcem-61-6-1126

9. SL Berga, SS Yen, Opioidergic regulation of LH pulsatility in women with polycystic ovary syndrome. Clin Endocrinol (Oxf). 30, 177-184 (1989). doi:10.1111/j.1365-2265.1989.tb03739.x

10. DA Ehrmann, Polycystic ovary syndrome. N Engl J Med. 352, 1223-1236 (2005). doi:10.1056/NEJMra041536

11. RJ Chang, A practical approach to the diagnosis of polycystic ovary syndrome. Am J Obstet Gynecol. 191, 713-717 (2004). doi:10.1016/.jajog.2004.04.045

12. A Dunaif, M Graf, J Mandeli, V Laumas, A Dobrjansky, Characterization of groups of hyperandrogenic women with acanthosis nigricans, impaired glucose tolerance, and/or hyperinsulinemia. J Clin Endocrinol Metab. 65 499-507 (1987). doi:10.1210/jcem-65-3-499

13. JE Nestler, Role of hyperinsulinemia in the pathogenesis of the polycystic ovary syndrome, and its clinical implications. Semin Reprod Endocrinol. 15, 111-122 (1997). doi:10.1055/s-2007-1016294

14. RL Barbieri, AR Gargiulo, Metformin for the treatment of the polycystic ovary syndrome. Minerva Ginecol. 56, 63-79 (2004)

15. S Palomba, R Oppedisano, A Tolino, F Orio, F Zullo, Outlook: metformin use in infertile patients with polycystic ovary syndrome: an evidence-based overview. Reprod Biomed Online. 16, 327-335 (2008). doi:10.1016/S14726483(10)60592-5

16. JM Lord, IH Flight, RJ Norman, Metformin in polycystic ovary syndrome: systematic review and meta-analysis. BMJ. 327, 951-953 (2003). doi:10.1136/ bmj.327.7421.951

17. EM Velazquez, S Mendoza, T Hamer, F Sosa, CJ Glueck, Metformin therapy in polycystic ovary syndrome reduces hyperinsulinemia, insulin resistance, hyperandrogenemia, and systolic blood pressure, while facilitating normal menses and pregnancy. Metabolism. 43, 647-654 (1994). doi:10.1016/00260495(94)90209-7

18. S Palomba, F Orio Jr, A Falbo, T Russo, A Tolino, F Zullo, Clomiphene citrate versus metformin as first-line approach for the treatment of anovulation in infertile patients with polycystic ovary syndrome. J Clin Endocrinol Metab. 92, 3498-3503 (2007). doi:10.1210/jc.2007-1009

19. C Brewer, S Acharya, F Thake, T Tang, A Balen, Effect of metformin taken in the 'fresh' in vitro fertilization/intracytoplasmic sperm injection cycle upon subsequent frozen embryo replacement in women with polycystic ovary syndrome. Hum Fertil (Camb). 13, 134-142 (2010). doi:10.3109/ 14647273.2010.504805

20. AA Creanga, HM Bradley, C McCormick, CT Witkop, Use of metformin in polycystic ovary syndrome: a meta-analysis. Obstet Gynecol. 111, 959-968 (2008). doi:10.1097/AOG.0b013e31816a4ed4

21. RS Legro, HX Barnhart, WD Schlaff, BR Carr, MP Diamond, SA Carson, MP Steinkampf, C Coutifaris, PG McGovern, NA Cataldo., et al, Clomiphene, metformin, or both for infertility in the polycystic ovary syndrome. N Engl J Med. 356, 551-566 (2007). doi:10.1056/NEJMoa063971

22. LO Tso, MF Costello, LE Albuquerque, RB Andriolo, V Freitas, Metformin treatment before and during IVF or ICSI in women with polycystic ovary syndrome. Cochrane Database Syst Rev. CD006105 (2009)
23. G Zhou, R Myers, Y Li, Y Chen, X Shen, J Fenyk-Melody, M Wu, J Ventre, T Doebber, N Fujii., et al, Role of AMP-activated protein kinase in mechanism of metformin action. J Clin Invest. 108, 1167-1174 (2001)

24. IP Salt, G Johnson, SJ Ashcroft, DG Hardie, AMP-activated protein kinase is activated by low glucose in cell lines derived from pancreatic beta cells, and may regulate insulin release. Biochem J. 335(Pt 3):533-539 (1998)

25. G da Silva Xavier, I Leclerc, IP Salt, B Doiron, DG Hardie, A Kahn, GA Rutter, Role of AMP-activated protein kinase in the regulation by glucose of islet beta cell gene expression. Proc Natl Acad Sci USA. 97, 4023-4028 (2000). doi:10.1073/pnas.97.8.4023

26. Y Minokoshi, T Alquier, N Furukawa, YB Kim, A Lee, B Xue, J Mu, F Foufelle, P Ferre, MJ Birnbaum., et al, AMP-kinase regulates food intake by responding to hormonal and nutrient signals in the hypothalamus. Nature. 428, 569-574 (2004). doi:10.1038/nature02440

27. U Andersson, K Filipsson, CR Abbott, A Woods, K Smith, SR Bloom, D Carling, CJ Small, AMP-activated protein kinase plays a role in the control of food intake. J Biol Chem. 279, 12005-12008 (2004)

28. Y Minokoshi, YB Kim, OD Peroni, LG Fryer, C Muller, D Carling, BB Kahn, Leptin stimulates fatty-acid oxidation by activating AMP-activated protein kinase. Nature. 415, 339-343 (2002). doi:10.1038/415339a

29. T Yamauchi, J Kamon, Y Minokoshi, Y Ito, H Waki, S Uchida, S Yamashita, M Noda, S Kita, K Ueki., et al, Adiponectin stimulates glucose utilization and fatty-acid oxidation by activating AMP-activated protein kinase. Nat Med. 8, 1288-1295 (2002). doi:10.1038/nm788

30. S Bilodeau-Goeseels, M Sasseville, C Guillemette, FJ Richard, Effects of adenosine monophosphate-activated kinase activators on bovine oocyte nuclear maturation in vitro. Mol Reprod Dev. 74, 1021-1034 (2007). doi:10.1002/mrd.20574

31. MA Mayes, MF Laforest, C Guillemette, RB Gilchrist, FJ Richard, Adenosine 5'-monophosphate kinase-activated protein kinase (PRKA) activators delay meiotic resumption in porcine oocytes. Biol Reprod. 76, 589-597 (2007). doi:10.1095/biolreprod.106.057828

32. J Chen, E Hudson, MM Chi, AS Chang, KH Moley, DG Hardie, SM Downs, AMPK regulation of mouse oocyte meiotic resumption in vitro. Dev Biol. 291, 227-238 (2006). doi:10.1016/j.ydbio.2005.11.039

33. L Tosca, P Solnais, P Ferre, F Foufelle, J Dupont, Metformin-induced stimulation of adenosine $5^{\prime}$ monophosphate-activated protein kinase (PRKA) impairs progesterone secretion in rat granulosa cells. Biol Reprod. 75, 342-351 (2006). doi:10.1095/biolreprod.106.050831

34. L Tosca, C Chabrolle, S Uzbekova, J Dupont, Effects of metformin on bovine granulosa cells steroidogenesis: possible involvement of adenosine $5^{\prime}$ monophosphate-activated protein kinase (AMPK). Biol Reprod. 76, 368-378 (2007). doi:10.1095/biolreprod.106.055749

35. L Tosca, C Rame, C Chabrolle, S Tesseraud, J Dupont, Metformin decreases IGF1-induced cell proliferation and protein synthesis through AMP-activated protein kinase in cultured bovine granulosa cells. Reproduction. 139, 409-418 (2010). doi:10.1530/REP-09-0351

36. SH Lee, KI Kwon, Pharmacokinetic-pharmacodynamic modeling for the relationship between glucose-lowering effect and plasma concentration of metformin in volunteers. Arch Pharm Res. 27, 806-810 (2004). doi:10.1007/ BF02980152

37. DL Coleman, KP Hummel, The influence of genetic background on the expression of the obese (Ob) gene in the mouse. Diabetologia. 9, 287-293 (1973). doi:10.1007/BF01221856

38. DL Coleman, Obese and diabetes: two mutant genes causing diabetesobesity syndromes in mice. Diabetologia. 14, 141-148 (1978). doi:10.1007/ BF00429772

39. AA Bachmanov, DR Reed, GK Beauchamp, MG Tordoff, Food intake, water intake, and drinking spout side preference of 28 mouse strains. Behav Genet. 32, 435-443 (2002). doi:10.1023/A:1020884312053

40. JL Tilly, Ovarian follicle counts-not as simple as 1, 2, 3. Reprod Biol Endocrinol. 1, 11 (2003). doi:10.1186/1477-7827-1-11

41. RS Legro, HX Barnhart, WD Schlaff, BR Carr, MP Diamond, SA Carson, MP Steinkampf, C Coutifaris, PG McGovern, NA Cataldo., et al, Ovulatory response to treatment of polycystic ovary syndrome is associated with a polymorphism in the STK11 gene. J Clin Endocrinol Metab. 93, 792-800 (2008)

42. A Dunaif, Insulin resistance and the polycystic ovary syndrome: mechanism and implications for pathogenesis. Endocr Rev. 18, 774-800 (1997). doi:10.1210/er.18.6.774 
43. EH Yu Ng, PC Ho, Polycystic ovary syndrome in asian women. Semin Reprod Med. 26, 14-21 (2008). doi:10.1055/s-2007-992920

44. E Moll, PM Bossuyt, JC Korevaar, CB Lambalk, F van der Veen, Effect of clomifene citrate plus metformin and clomifene citrate plus placebo on induction of ovulation in women with newly diagnosed polycystic ovary syndrome: randomised double blind clinical trial. BMJ. 332, 1485 (2006). doi:10.1136/bmj.38867.631551.55

45. GN Allahbadia, R Merchant, Polycystic ovary syndrome in the Indian Subcontinent. Semin Reprod Med. 26, 22-34 (2008). doi:10.1055/s-2007992921

46. S Rice, L Pellatt, K Ramanathan, SA Whitehead, HD Mason, Metformin inhibits aromatase via an extracellular signal-regulated kinase-mediated pathway. Endocrinology. 150, 4794-4801 (2009). doi:10.1210/en.2009-0540

47. G Onalan, B Selam, Y Baran, M Cincik, R Onalan, U Gunduz, AU Ural, R Pabuccu, Serum and follicular fluid levels of soluble Fas, soluble Fas ligand and apoptosis of luteinized granulosa cells in PCOS patients undergoing IVF. Hum Reprod. 20, 2391-2395 (2005). doi:10.1093/humrep/dei068

48. A Marciniak, J Nawrocka-Rutkowska, A Brodowska, R Sienkiewicz, I Szydlowska, A Starczewski, Leptin concentrations in patients with polycystic ovary syndrome before and after met-formin treatment depending on insulin resistance, body mass index and androgen con-centrationsintroductory report. Folia Histochem Cytobiol. 47, 323-328 (2009). doi:10.2478/v10042-009-0032-0

49. S Franks, C Gilling-Smith, H Watson, D Willis, Insulin action in the normal and polycystic ovary. Endocrinol Metab Clin North Am. 28, 361-378 (1999). doi:10.1016/S0889-8529(05)70074-8

50. MC Richardson, S Ingamells, CD Simonis, IT Cameron, R Sreekumar, A Vijendren, L Sellahewa, S Coakley, CD Byrne, Stimulation of lactate production in human granulosa cells by metformin and potential involvement of adenosine $5^{\prime}$ monophosphate-activated protein kinase. J Clin Endocrinol Metab. 94, 670-677 (2009). doi:10.1210/jc.2008-2025

51. S Palomba, A Falbo, T Russo, F Orio, A Tolino, F Zullo, Systemic and local effects of metformin administration in patients with polycystic ovary syndrome (PCOS): relationship to the ovulatory response. Hum Reprod. 25 1005-1013 (2010). doi:10.1093/humrep/dep466

52. D Shi, MK Dyck, RR Uwiera, JC Russell, SD Proctor, DF Vine, A unique rodent model of cardiometabolic risk associated with the metabolic syndrome and polycystic ovary syndrome. Endocrinology. 150, 4425-4436 (2009). doi:10.1210/en.2008-1612

53. L Manneras, S Cajander, A Holmang, Z Seleskovic, T Lystig, M Lonn, E Stener-Victorin, A new rat model exhibiting both ovarian and metabolic characteristics of polycystic ovary syndrome. Endocrinology. 148, 3781-3791 (2007). doi:10.1210/en.2007-0168

54. RJ Shaw, KA Lamia, D Vasquez, SH Koo, N Bardeesy, RA Depinho, M Montminy, LC Cantley, The kinase LKB1 mediates glucose homeostasis in liver and therapeutic effects of metformin. Science. 310, 1642-1646 (2005). doi:10.1126/science. 1120781

55. ᄂ Pellatt, S Rice, HD Mason, Phosphorylation and activation of AMPactivated protein kinase (AMPK) by metformin in the human ovary requires insulin. Endocrinology. 152, 1112-1118 (2011). doi:10.1210/en.2009-1429

doi:10.1186/1757-2215-4-8

Cite this article as: Sabatini et al:: Metformin therapy in a

hyperandrogenic anovulatory mutant murine model with polycystic ovarian syndrome characteristics improves oocyte maturity during superovulation. Journal of Ovarian Research 2011 4:8.

\section{Submit your next manuscript to BioMed Central and take full advantage of:}

- Convenient online submission

- Thorough peer review

- No space constraints or color figure charges

- Immediate publication on acceptance

- Inclusion in PubMed, CAS, Scopus and Google Scholar

- Research which is freely available for redistribution

Submit your manuscript at www.biomedcentral.com/submit
C Biomed Central 